\title{
Potential vasorelaxant effects of oleanolic acid and erythrodiol, two triterpenoids contained in 'orujo' olive oil, on rat aorta
}

\author{
Rosalía Rodríguez-Rodríguez ${ }^{1}$, María Dolores Herrera ${ }^{2}$, Javier S. Perona ${ }^{1}$ and \\ Valentina Ruiz-Gutiérrez ${ }^{1}$. \\ ${ }^{1}$ Instituto de la Grasa, Consejo Superior de Investigaciones Científicas, Avda Padre García Tejero n. 4, 41012 Sevilla, \\ Spain \\ ${ }^{2}$ Departamento de Farmacología, Facultad de Farmacia, Universidad de Sevilla, C/Profesor García González n. 2 , \\ 41012 Sevilla, Spain
}

(Received 13 February 2004 - Revised 20 May 2004 - Accepted 3 June 2004)

\begin{abstract}
'Orujo' olive oil is obtained by chemical processes from the waste resulting from the mechanical extraction of virgin olive oil. The aim of the present study was to evaluate a new pharmacological property of two natural triterpenoids contained in olive oil, as vasodilatory agents, and to determine their mechanism of action. The two compounds studied were oleanolic acid and erythrodiol. The vasorelaxant effect induced by these pentacyclic triterpenoids was studied in isolated thoracic rat aorta. Oleanolic acid and erythrodiol, accumulatively added, showed vasorelaxant activities in aortic rings with endothelium pre-contracted by $10^{-6} \mathrm{M}$-phenylephrine (maximum percentage of relaxation 86.38 (SEM 2.89) and 73.53 (SEM 6.01), respectively). They had almost no relaxant effect on depolarised or endotheliumdenuded aortic segments. The relaxation was significantly attenuated by pre-treatment with the NO synthase inhibitor $\mathrm{N}^{\omega}$-nitro-L-arginine-methylester (L-NAME; $3 \times 10^{-4} \mathrm{M}$ ). To characterise the involvement of endothelial factors, in addition to NO, arteries with endothelium were exposed to $10^{-5} \mathrm{M}$-indomethacin (INDO), a cyclo-oxygenase inhibitor, or INDO plus L-NAME. INDO did not have any significant effect on the relaxant response of both compounds. The combination of L-NAME plus INDO only abolished the oleanolic acid-induced relaxation. The present results suggest that the mechanism of relaxation seems to be mainly mediated by the endothelial production of NO; however, other mechanisms cannot be excluded. It can be concluded that oleanolic acid and erythrodiol may have interesting therapeutic potential as new vasodilator drugs, thus protecting the cardiovascular system. Therefore, the intake of 'orujo' olive oil, as a source of these compounds, might be beneficial in this regard.
\end{abstract}

'Orujo' olive oil: Oleanolic acid: Erythrodiol: Vasorelaxation: Endothelium: Rat aorta

Epidemiological studies and clinical trials demonstrate that a suitable diet may reduce the occurrence of cardiovascular disorders (Keys, 1995). In recent years, there has been a growing interest in fortified and enhanced foods, referred to as 'functional foods' or 'nutraceuticals'. It is noteworthy that phytochemicals or components in these functional foods, when consumed at effective levels as part of a varied diet, may provide some health benefits (American Dietetic Association, 1999).

The importance of olive oil as an integral ingredient of the Mediterranean diet is well known, and some evidence suggests that it may have health benefits on inflammatory and cardiovascular events (Visioli \& Galli, 1998; De la Puerta et al. 1999; Perona \& Ruíz-Gutiérrez, 2000). The varied olive oil components seem to be responsible for these therapeutic characteristics.

'Orujo' olive oil, as called in Spain, is obtained by chemical processes from the mechanical extraction of virgin olive oil. To our knowledge, the potential therapeutic significance of this olive sub-product has not yet been studied. It is expected that subsequent investigations will allow the discovery of the functional properties of 'orujo' olive oil, due to its potentially beneficial components (e.g. tetra- and pentacyclic triterpenes), which are in a lower concentration in virgin and refined olive oil (Vioque \& Maza, 1963; Vázquez-Roncero \& Janer, 1969). The present study is focused on oleanolic acid (3ß-hydroxyolean-12-en-28-oic acid) and erythrodiol

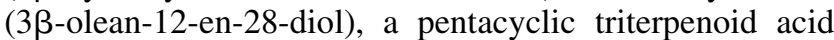
and alcohol respectively (Fig. 1). The solid waste called 'orujo' resulting from the olive oil extraction contains a blend of olive leaves, cuticle and surface, which are a source of these triterpenoids. Thus, 'orujo' oil contains oleanolic acid and erythrodiol in a high concentration, in contrast to olive oil (Vioque \& Morris, 1961; PérezCamino \& Cert, 1999).

\footnotetext{
Abbreviations: COX, cyclo-oxygenase; INDO, indomethacin; L-NAME, $\mathrm{N}^{\omega}$-nitro-L-arginine-methylester; SOD, superoxide dismutase; Tp, thromboxane $\mathrm{A}_{2}$ - prostaglandin $\mathrm{H}_{2}$.

*Corresponding author: Dr V. Ruiz-Gutiérrez, fax +34 954616790, email valruiz@cica.es
} 


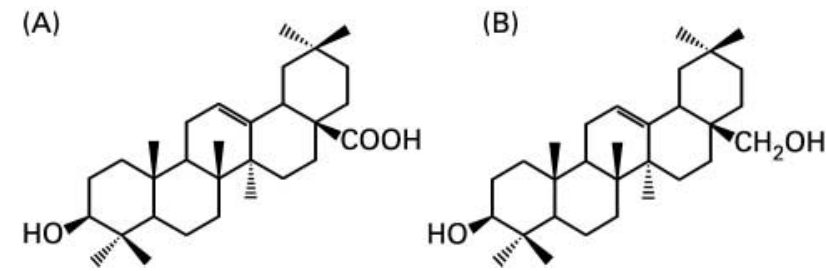

Fig. 1. Chemical structures of $(A)$ oleanolic acid and (B) erythrodiol.

The pharmacological effects of erythrodiol have not been studied in detail. Only the therapeutic efficiency of erythrodiol on different experimental models of inflammation has been reported (Recio et al. 1995; Mañez et al. 1997; De la Puerta et al. 2000). However, many studies on oleanolic acid have been published. These reports have demonstrated a very wide range of biological and pharmacological properties of this triterpenoid acid. Many of them were summarised by Liu (1995). These properties include, among others, anti-inflammatory (Ringbom et al. 1998; Honda et al. 2000), anti-tumoral (Hsu et al. 1997; Choi et al. 2001), hepatoprotective (Liu et al. 1998; Yim et al. 2001), anti-diabetogenic (Matsuda et al. 1998; Yoshikawa \& Matsuda, 2000) and anti-HIV activities (Kashiwada et al. 1998; Zhu et al. 2001; Mengoni et al. 2002). There is scarce evidence about the pharmacological effects of erythrodiol and oleanolic acid on vascular events; only the cardiovascular effects of oleanolic acid and its isomer ursolic acid have been recently studied and published by Somova et al. $(2003 a, b)$. They have shown that the chronic treatment of Dahl salt-sensitive hypertensive rats with these natural compounds prevents the development of hypertension with significant bradycardia and potent diuretic activity.

Our interest in both oleanolic acid and erythrodiol on the cardiovascular system arises from their anti-inflammatory properties mentioned earlier. Inflammation has been recently linked to the atherogenic process, which also impairs endothelial function (Libby, 2002), and it is related to vascular reactivity. Therefore, we now report for the first time a study of the possible vasodilatory effects of oleanolic acid and erythrodiol in rat thoracic aorta and the influence of endothelium-derived factors in these actions. The underlying mechanism implicated in their vasorelaxant responses was also investigated, using different experimental protocols.

\section{Materials and methods}

\section{Experimental animals}

The pharmacological experiments were carried out on adult male Wistar rats (10-12 weeks old) weighing 250-300 g, and fed on standard rat chow with free access to drinking water. All experiments were performed according to the guidelines for the ethnical treatment of animals of the European Union.

\section{Aortic ring preparation}

The animals were killed by cervical dislocation and the descending thoracic aorta was rapidly dissected and transferred into modified Krebs-Henseleit solution of the following composition (mM): $\mathrm{NaCl}, 118 ; \mathrm{KCl}, 4.75$; $\mathrm{NaHCO}_{3}, 25 ; \mathrm{MgSO}_{4}, 1 \cdot 2 ; \mathrm{CaCl}_{2}, 1.8 ; \mathrm{KH}_{2} \mathrm{PO}_{4}, 1 \cdot 2$; glucose, 11.

The aortas were cleaned of adherent tissue and cut into $2-3 \mathrm{~mm}$ rings. Each ring was fixed horizontally under a resting tension of $2 \mathrm{~g}$ in a $10 \mathrm{ml}$ organ-bath filled with Krebs-Henseleit solution. The solution was continuously kept at $37^{\circ} \mathrm{C}$ and gassed with $95 \% \mathrm{O}_{2}$ and $5 \% \mathrm{CO}_{2}$ at $\mathrm{pH}$ 7.4. Mechanical activity was recorded isometrically by a force-displacement transducer (Pioden UF-1; Pioden Controls Ltd, Canterbury, Kent, UK) connected to a Powerlab data acquisition system (ADInstruments Pty Ltd; Castle Hill, New South Wales, Australia), as previously described (Álvarez de Sotomayor et al. 2001).

After an equilibration period of $60 \mathrm{~min}$, aortic rings were contracted with $10^{-6} \mathrm{M}$-phenylephrine to test their contractile capacity. In some experiments, the endothelial layer was removed immediately after dissection by gently rubbing the intimal surface of the intact vessel. The presence of functional endothelium was confirmed in all preparations by determining the ability of $10^{-6} \mathrm{M}$-acetylcholine to induce more than $50 \%$ relaxation of rings pre-contracted with $10^{-6} \mathrm{M}$-phenylephrine. The absence of a relaxation response to acetylcholine was taken as evidence that the aortic segments were functionally denuded of endothelium.

\section{Vascular relaxation experiments}

For the assessment of vasorelaxation property and potency, the aortic rings were first pre-contracted at $80 \%$ of their maximal contraction with $10^{-6} \mathrm{M}$-phenylephrine or $\mathrm{KCl}$ $(25$ or $80 \mathrm{~mm})$. When the contractile responses reached a plateau, cumulative concentrations of oleanolic acid or erythrodiol $\left(10^{-7}\right.$ to $\left.10^{-4} \mathrm{M}\right)$ were added to the bath medium at $20 \mathrm{~min}$ intervals (the time necessary to obtain a steadystate relaxation) to study the relaxation induced by these two compounds. The same procedure was repeated in endothelium-denuded aortic rings.

We also performed another set of experiments, in order to elucidate the mechanism of action of oleanolic acid and erythrodiol. Rings with functional endothelium were preincubated with the following inhibitors: the NO synthase inhibitor $\mathrm{N}^{\omega}$-nitro-L-arginine methyl ester (L-NAME; $\left.3 \times 10^{-4} \mathrm{M}\right)$, the cyclo-oxygenase (COX) inhibitor indomethacin (INDO; $10^{-5} \mathrm{M}$ ), the thromboxane $\mathrm{A}_{2}$ - prostaglandin $\mathrm{H}_{2}$ receptor (Tp) antagonist, ICI 192,605 $\left(10^{-5} \mathrm{M}\right)$, or a combination of the superoxide anion $\left(\mathrm{O}_{2}^{-}\right)$scavenger, superoxide dismutase (SOD; $150 \mathrm{U} / \mathrm{ml}$ ) plus the $\mathrm{H}_{2} \mathrm{O}_{2}$ inactivator, catalase $(1000 \mathrm{U} / \mathrm{ml})$. Sarcoplasmic reticulum $\mathrm{Ca}^{2+}$-ATPase involvement was investigated by using $3 \times 10^{-5}$ M-cyclopiazonic acid, added to the bath at the same time as phenylephrine. L-NAME and INDO were incubated with the tissues for $20 \mathrm{~min}$ before the pre-contraction with the agonist. ICI 192,605 was incubated for $30 \mathrm{~min}$, and the combination of SOD plus catalase was added $15 \mathrm{~min}$ before the agonist application. Different aortic rings from different animals were used in each experiment. All the results were expressed as a percentage of the maximal contraction of phenylephrine-induced responses. 


\section{Drugs}

The following drugs were used: oleanolic acid and erythrodiol (Extrasynthese, Genay, France), acetylcholine chloride, INDO, L-NAME, phenylephrine hydrochloride, superoxide dismutase and catalase (Sigma Chemical Co., St Louis, MO, USA), and ICI 192,605 and cyclopiazonic acid (Tocris, Biogen Cientifica S.L., Madrid, Spain). Stock solutions were prepared in distilled deionised water except oleanolic acid, erythrodiol, INDO, ICI 192,605 and cyclopiazonic acid, which were dissolved in dimethylsulfoxide. The final dimethylsulfoxide concentration $(<0 \cdot 01 \%)$ in the tissue-bath did not significantly influence vascular responses. All concentrations of the drugs used are expressed as their final concentration in the organ chamber.

\section{Statistical analysis}

Results are expressed as percentages from the initial precontraction level and as mean values and standard errors of the mean of six to eight rats per group. Dose-response slopes were analysed to give the concentration of oleanolic acid and erythrodiol required to produce $50 \%$ of the maximal relaxation. Statistically significant differences were evaluated by an ANOVA followed by the least significant difference test. $P$ values of $<0.05$ were considered to indicate a significant difference. In figures, all error bars have been removed, since they are smaller than the symbol size. The data analyses were performed with the GraphPad Prism ${ }^{\circledR}$ statistical package (version 3.00; GraphPad Software Inc., San Diego, CA, USA).

\section{Results}

Effects on phenylephrine-induced contractions: influence of endothelium

As illustrated in Fig. 2, oleanolic acid and erythrodiol induced a vasorelaxant response in a concentration-dependent manner in endothelium-intact aortas pre-contracted by $10^{-6} \mathrm{M}$-phenylephrine. The vasorelaxant effect of these triterpenoids was also analysed in mechanically denuded aortas. Removal of the endothelium markedly attenuated the relaxant effects on contractions evoked by phenylephrine (Fig. 2). The maximal response to oleanolic acid or erythrodiol at $10^{-4} \mathrm{M}$ was decreased in aortic rings without endothelium (Table 1).

\section{Effects on potassium chloride-induced contractions}

The effects of oleanolic acid and erythrodiol on low $(25 \mathrm{mM})$ and high $(80 \mathrm{~mm}) \mathrm{KCl}$-evoked contractions were studied. In aortic rings with an intact endothelial layer pre-contracted by $25 \mathrm{mM}-\mathrm{KCl}$, both triterpenoids elicited a moderate vasorelaxation (Fig. 3), with lower values of maximum percentage of relaxation, compared with those obtained in phenylephrine-contracted aortas. The maximal relaxant effects of both triterpenoids in depolarised aortas $(80 \mathrm{mM}-\mathrm{KCl})$ were significantly lower than those obtained in $25 \mathrm{mM}-\mathrm{KCl}$-pre-contracted aortic segments (Table 1).
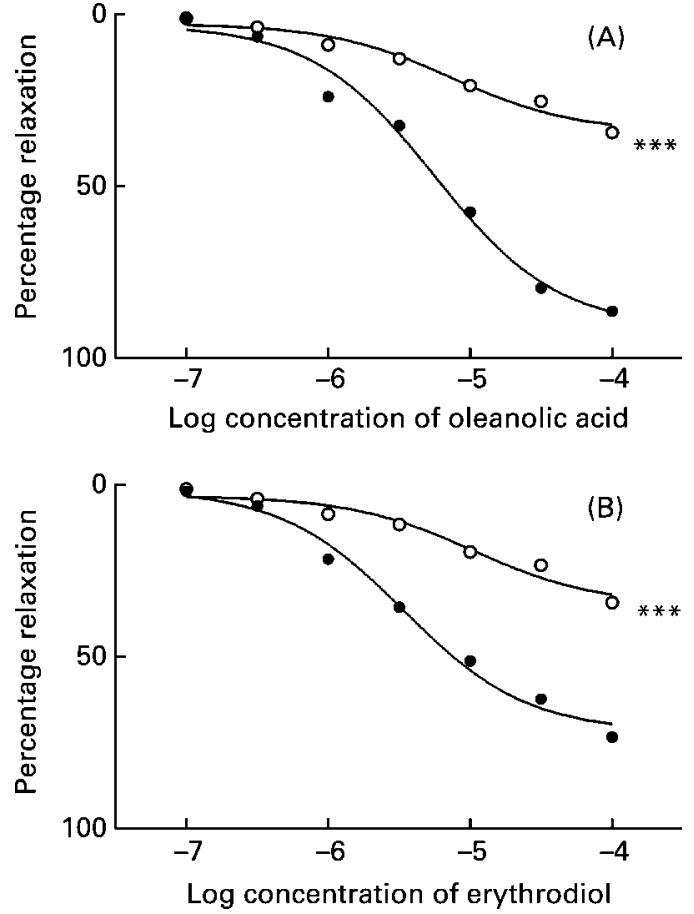

Fig. 2. Relaxant effects of oleanolic acid (A) and erythrodiol (B) in aortic rings pre-contracted by $10^{-6} \mathrm{M}$-phenylephrine. (•), Control arteries with intact endothelium; (०), denuded arteries. Values are means for six rats per group. ${ }^{* \star}$ Response curve was significantly different from that for the control with endothelium $(P<0.001)$.

\section{Characterisation of endothelial factors involved in the relaxant effect}

To measure the influence of NO on the endothelium-dependent relaxation induced by oleanolic acid or erythrodiol, the effect of the NO synthase inhibitor, L-NAME $\left(3 \times 10^{-4} \mathrm{M}\right)$, was studied. In these conditions, L-NAME produced a significant reduction of the relaxation induced by both triterpenic compounds in endothelium-intact rat aortic rings (Fig. 4). In another set of experiments, the involvement of prostanoids derived from the COX pathway in the vasorelaxation was also tested. Some differences between oleanolic acid responses and erythrodiol responses were observed.

The blockage of COX by $10^{-5} \mathrm{M}$-INDO did not affect the oleanolic acid-induced relaxation. However, when NO synthase and COX were blocked together, the relaxation response was significantly attenuated and this finding was similar to that obtained in denuded arteries, as shown in Fig. 5 (A). When the aortas were incubated with the Tp receptor antagonist ICI $192,605\left(10^{-5} \mathrm{M}\right)$, the relaxation of arteries pre-contracted with phenylephrine induced by oleanolic acid was not altered (Fig. 6 (A)).

On the other hand, for erythrodiol, pre-treatment of the rings with $10^{-5} \mathrm{M}$-INDO did not affect the endothelium-dependent vasorelaxation (Fig. 5 (B)). In contrast to oleanolic acid, exposure to $10^{-5} \mathrm{M}-\mathrm{INDO}$ plus $3 \times 10^{-4} \mathrm{M}-\mathrm{L}-\mathrm{NAME}$ did not result in a further alteration in relaxation induced by erythrodiol compared with INDO alone. Fig. 6 (B) shows that $10^{-5}$ M-ICI 192,605 was able to slightly but significantly $(P<0.05)$ increase 
Table 1. Maximum percentage of relaxation $\left(E_{\max }\right)$ induced by oleanolic acid and erythrodiol and concentrations of oleanolic acid and erythrodiol required to produce $50 \%$ of $\mathrm{E}_{\max }\left(\mathrm{EC}_{50}\right)$ in intact or denuded aortic rings pre-contracted by $10^{-6} \mathrm{M}$-phenylephrine or potassium chloride ( 80 or $25 \mathrm{~mm}$ ) (six to eight rats per group)

(Mean values and standard errors of the mean)

\begin{tabular}{|c|c|c|c|c|c|c|c|c|}
\hline & \multicolumn{4}{|c|}{ Oleanolic acid } & \multicolumn{4}{|c|}{ Erythrodiol } \\
\hline & \multicolumn{2}{|c|}{$E_{\max }(\%)$} & \multicolumn{2}{|c|}{$\mathrm{EC}_{50}(\mu \mathrm{M})$} & \multicolumn{2}{|c|}{$\mathrm{E}_{\max }(\%)$} & \multicolumn{2}{|c|}{$\mathrm{EC}_{50}(\mu \mathrm{M})$} \\
\hline & Mean & SEM & Mean & SEM & Mean & SEM & Mean & SEM \\
\hline \multicolumn{9}{|l|}{ Endothelium intact } \\
\hline Phenylephrine & $86 \cdot 38$ & $2 \cdot 89$ & 5.58 & 1.28 & 73.54 & 6.01 & $3 \cdot 38$ & 1.27 \\
\hline L-NAME & $28 \cdot 15^{\star \star \star}$ & 2.96 & ND & & $25 \cdot 50^{\star \star \star}$ & 3.85 & ND & \\
\hline INDO & 80.54 & 3.94 & 14.5 & 1.54 & 57.70 & $6 \cdot 76$ & $3 \cdot 86$ & 1.41 \\
\hline INDO + L-NAME & $43 \cdot 90^{\star \star *}$ & 4.97 & ND & & 70.33 & 8.52 & $5 \cdot 22$ & 1.20 \\
\hline ICl 192,605 & $72 \cdot 14$ & 6.45 & 0.63 & 1.47 & 74.94 & $6 \cdot 87$ & 0.69 & 1.37 \\
\hline $\mathrm{ICI}+$ L-NAME & $36 \cdot 95^{\star \star *}$ & 4.54 & ND & & $43 \cdot 56^{\star \star \star}$ & 3.85 & ND & \\
\hline CPA & $12 \cdot 55^{\star \star \star}$ & $9 \cdot 16$ & ND & & $23 \cdot 39^{\star \star \star}$ & 6.94 & ND & \\
\hline $\mathrm{KCl}(80 \mathrm{~mm})$ & $29 \cdot 71^{\star \star *}$ & 3.55 & ND & & $27 \cdot 02^{\star \star \star}$ & $6 \cdot 69$ & ND & \\
\hline $\mathrm{KCl}(25 \mathrm{~mm})$ & $52 \cdot 33^{\star \star *}$ & $6 \cdot 30$ & 12.5 & 1.77 & $39 \cdot 25^{\star \star \star}$ & 3.06 & ND & \\
\hline \multicolumn{9}{|l|}{ Endothelium denuded } \\
\hline Phenylephrine & $34.42^{\star \star \star}$ & $3 \cdot 28$ & ND & & $34 \cdot 38^{\star \star \star}$ & $2 \cdot 79$ & ND & \\
\hline CPA & $48 \cdot 64^{\star \star *}$ & 4.07 & ND & & $46 \cdot 92^{\star \star *}$ & $5 \cdot 14$ & ND & \\
\hline $\mathrm{KCl}(80 \mathrm{~mm})$ & $33 \cdot 00^{* \star *}$ & $4 \cdot 21$ & ND & & $32 \cdot 00^{\star \star \star}$ & 3.59 & ND & \\
\hline $\mathrm{KCl}(25 \mathrm{~mm})$ & $54.46^{\star \star *}$ & 5.91 & 4.73 & 1.55 & $60.91^{\star *}$ & 4.70 & 5.98 & 1.62 \\
\hline
\end{tabular}

L-NAME, $\mathrm{N}^{\omega}$-nitro-L-arginine methylester; ND, could not be calculated; INDO, indomethacin; CPA, cyclopiazonic acid. Mean value was significantly different from that for intact aorta pre-contracted by phenylephrine: ${ }^{\star \star} P<0 \cdot 01,{ }^{\star \star \star} P<0 \cdot 001$

For details of drugs and procedures, see pp. 636-637.

the endothelial relaxant response to erythrodiol in intact arteries. However, the concentration-response curve to erythrodiol was significantly different in the presence of ICI 192,605 alone or in combination with L-NAME.
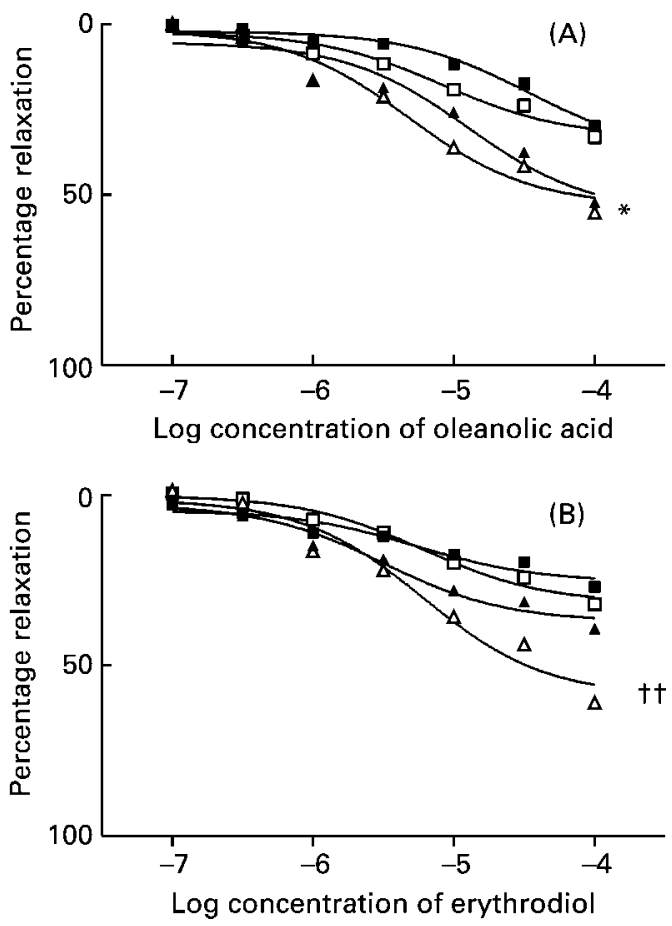

Fig. 3. Relaxant effects of oleanolic acid (A) and erythrodiol (B) in aortic rings pre-contracted by $80 \mathrm{~mm}-\mathrm{KCl}$ with (-) and without (口) endothelium, or by $25 \mathrm{~mm}-\mathrm{KCl}$ with $(\Delta)$ and without $(\Delta)$ endothelium. Values are means for six rats per group. *Response curve was significantly different from that for intact aorta pre-contracted by $80 \mathrm{~mm}-\mathrm{KCl}(P<0.05)$. ††Response curve was significantly different from that for denuded aorta pre-contracted by $80 \mathrm{~mm}-\mathrm{KCl}(P<0.01)$.
Finally, to test whether an augmented production of superoxide anion and $\mathrm{H}_{2} \mathrm{O}_{2}$ is involved in the endothelium-dependent relaxation induced by oleanolic acid or erythrodiol, arteries were pre-treated with SOD
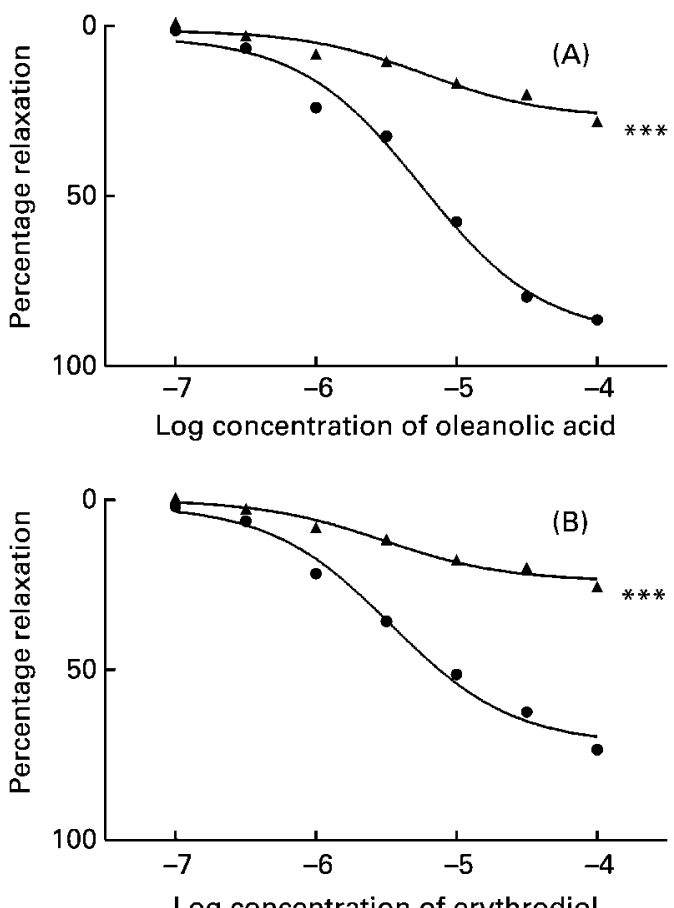

Log concentration of erythrodiol

Fig. 4. Relaxant effects of oleanolic acid (A) and erythrodiol (B) in aortic rings with functional endothelium pre-contracted by $10^{-6}$ M-phenylephrine. (๑), Control arteries; $(\mathbf{\Lambda})$, arteries in the presence of $3 \times 10^{-4} \mathrm{M}-\mathrm{N}^{\omega}$-nitro-L-arginine-methylester. Values are means for six rats per group. ${ }^{* *}$ Response curve was significantly different from that for the control $(P<0.001)$. 

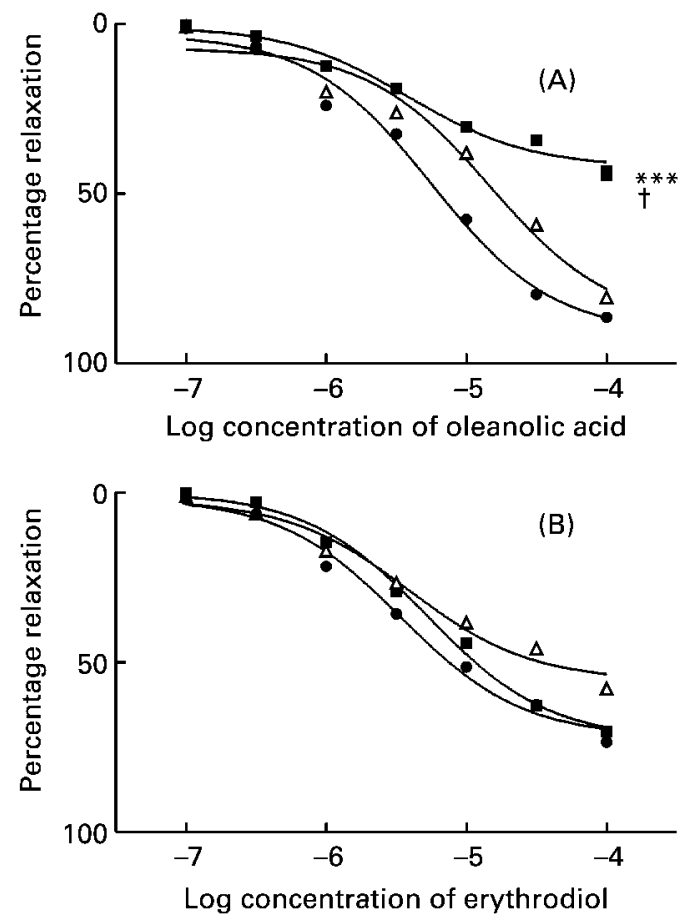

Fig. 5. Relaxant effects of oleanolic acid (A) and erythrodiol (B) in aortic rings with functional endothelium pre-contracted by $10^{-6} \mathrm{M}$-phenylephrine. $(\bullet)$, Control arteries; $(\Delta)$, arteries in the presence of $10^{-5} \mathrm{M}$-indomethacin (INDO); ( $\mathbf{m}$ ), arteries in the presence of $10^{-5} \mathrm{M}$-INDO plus $3 \times 10^{-4} \mathrm{M}-\mathrm{N}^{\omega}$-nitro-L-arginine-methylester. Values are means for six to eight rats per group. ${ }^{* * *}$ Response curve was significantly different from that for the control $(P<0.001)$. †Response curve was significantly different from that for aortic rings in the presence of $10^{-5} \mathrm{M}$-INDO alone $(P<0.05)$.

$(150 \mathrm{U} / \mathrm{ml})$ plus catalase $(1000 \mathrm{U} / \mathrm{ml})$. But, as shown in Fig. 7, the relaxations due to oleanolic acid or erythrodiol were not affected by the combination of these reactive oxygen species scavengers.

Effect of $\mathrm{Ca}^{2+}-$ ATPase inhibition on oleanolic acid and erythrodiol-induced relaxations

Inhibition of sarcoplasmic reticulum $\mathrm{Ca}^{2+}-\mathrm{ATPase}$ with $3 \times 10^{-5} \mathrm{M}$-cyclopiazonic acid was able to significantly decrease the relaxant effects of oleanolic acid and erythrodiol in aortic rings with endothelium (Fig. 8). On the other hand, in endothelium-denuded arteries, the presence of cyclopiazonic acid slightly increased the relaxation induced by oleanolic acid or erythrodiol (Fig. 8).

\section{Discussion}

The present study investigates, for the first time, the vasorelaxant activity of oleanolic acid and erythrodiol in rat aorta. In the present experiments, we have studied the ability of both compounds, accumulatively added to the organ-bath medium, to induce a relaxation of contractions caused by different agonists, $\mathrm{KCl}$ or phenylephrine, in isolated rat aorta. The results clearly show that oleanolic acid and erythrodiol are able to relax, in a concentration-dependent fashion, the contractions induced by phenylephrine in rat aortic rings with functional endothelium. However, these
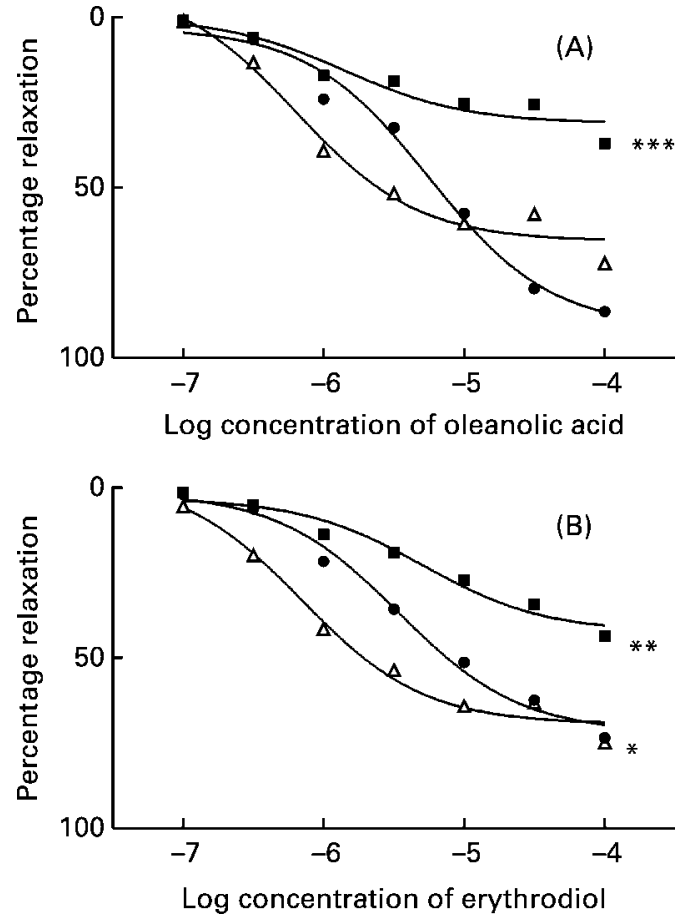

Fig. 6. Relaxant effects of oleanolic acid (A) and erythrodiol (B) in aortic rings with functional endothelium pre-contracted by $10^{-6} \mathrm{M}$-phenylephrine. $(\bullet)$, Control arteries; $(\Delta)$, arteries in the presence of $10^{-5} \mathrm{M}-\mathrm{ICl} 192,605 ;(\mathbf{m})$, arteries in the presence of $10^{-5}$ $\mathrm{M}-\mathrm{ICl} 192,605$ plus $3 \times 10^{-4} \mathrm{M}-\mathrm{N}^{\omega}$-nitro-L-arginine-methylester. Values are means for six rats per group. Response curves were significantly different from control: ${ }^{\star} P<0.05, \quad{ }^{\star \star} P<0.01$, $\star \star \star P<0.001$.
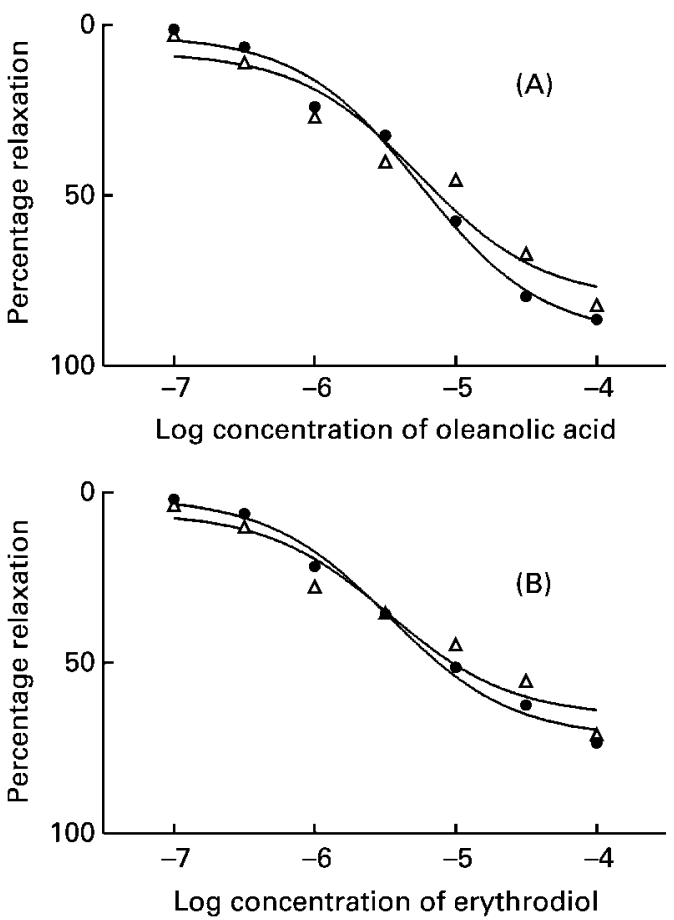

Fig. 7. Relaxant effects of oleanolic acid (A) and erythrodiol (B) in aortic rings with functional endothelium pre-contracted by $10^{-6} \mathrm{M}$-phenylephrine. $(\bullet)$, Control arteries; $(\Delta)$, arteries in the presence of superoxide dismutase $(150 \mathrm{U} / \mathrm{ml})$ plus catalase $(1000 \mathrm{U} / \mathrm{ml})$. Values are means for six rats per group. 

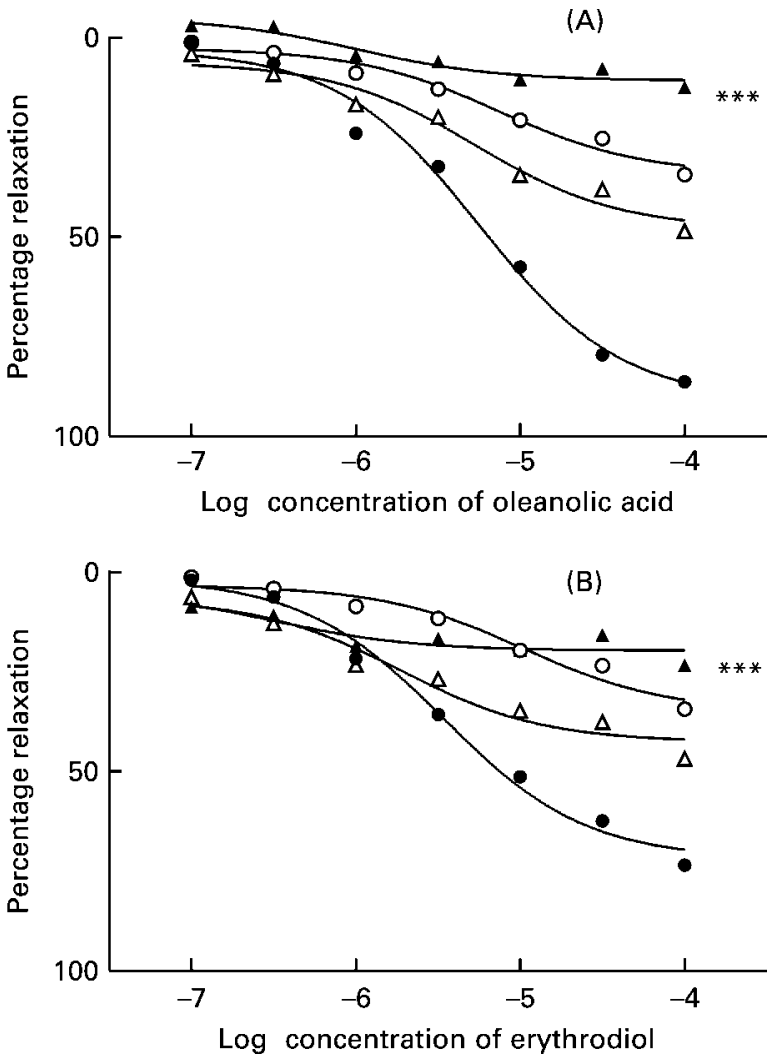

Fig. 8. Effects of oleanolic acid (A) and erythrodiol (B) in aortic rings pre-contracted by $10^{-6} \mathrm{M}$-phenylephrine. (๑), Control arteries with intact endothelium; (०), denuded arteries; (1), arteries with endothelium in the presence of $3 \times 10^{-5} \mathrm{M}$-cyclopiazonic acid; $(\Delta)$, arteries without endothelium in the presence of $3 \times 10^{-5}$ M-cyclopiazonic acid. Values are means for six to eight rats per group. ${ }^{\star \star \star}$ Response curve was significantly different from that for the control with endothelium $(P<0.001)$.

responses were less marked in arteries pre-contracted by $\mathrm{KCl}$ and in endothelium-denuded arteries. It is has been reported that high $\mathrm{K}^{+}$concentrations cause contractions in vascular smooth muscle by depolarising cell membranes and by increasing the influx of $\mathrm{Ca}^{2+}$ through long-lasting voltagedependent channels (Godfraind et al. 1986). In this way, the absence of relaxation in $80 \mathrm{mM}-\mathrm{KCl}$-evoked contractions might probably remove either the influence of membrane hyperpolarisation or the contribution of the blockage of $\mathrm{Ca}$ entry through voltage-stimulated $\mathrm{Ca}^{2+}$ channels to the relaxant responses to oleanolic acid and erythrodiol.

The vascular endothelium has been shown by Furchgott \& Zawadzki (1980) to be of crucial importance in the relaxation of blood vessels in response to acetylcholine and some other naturally occurring vasodilator substances (Furchgott \& Vanhoutte, 1989). Although NO appears to be the major vasodilator released by endothelial cells, other substances may also play a role, including prostacyclin and the endothelium-derived hyperpolarising factor. These endothelial-relaxing factors contribute to the protective role of the endothelium (Boulanger, 1999). It has become clear that endothelial cells not only release relaxing factors but also produce contracting substances such as endothelin, thromboxane $\mathrm{A}_{2}$ and prostaglandin $\mathrm{H}_{2}$ (Moncada et al. 1991) as well as reactive oxygen species
(Lüscher \& Barton, 1997). The present in vitro study shows that the absence of the endothelial layer significantly attenuates the relaxant effects of oleanolic acid and erythrodiol. This indicates that these effects are due to an indirect and/or direct action of both triterpenic compounds on the vascular endothelium, increasing the release of endogenous relaxing factors and/or inhibiting the production of contracting factors derived from endothelium.

It has been previously reported in a well-established in vitro model of vasomotion that triterpenoid-related compounds, commonly found in plant species, elicit vasorelaxation through the direct release of NO from vascular endothelium (Kim et al. 1994; Tanner et al. 1999). In this way, it was expected that oleanolic acid and erythrodiol would have vasoactive effects related to NO derived from endothelium. The present experiments have indeed demonstrated an NO-mediated mechanism, since the endothelium-dependent relaxation due to oleanolic acid or erythrodiol was blocked by pre-incubating the arteries with the NO synthase inhibitor L-NAME. However, we cannot rule out the participation of other mechanisms of action in the vasorelaxant activity.

According to the relaxant effect of erythrodiol, NO did not seem to be the only endothelial factor released by this triterpenic alcohol addition. This conclusion is supported by the results obtained with the COX inhibitor and with the Tp receptor antagonist. It is important to point out that erythrodiol induced a persisting relaxation in the presence of the simultaneous blockage of the NO release and the COX pathway. In addition, a higher relaxation was observed in the presence of the Tp receptor antagonist. The relaxant effect induced by erythrodiol was more emphatic in the absence of thromboxane $\mathrm{A}_{2}$-prostaglandin $\mathrm{H}_{2}$ or Tp receptor action. The data reveal the possible participation of these endothelial vasoconstrictor products upon erythrodiol stimulation. The most likely candidate for the endothelial vasoconstrictor factor from COX is probably thromboxane $\mathrm{A}_{2}$ or other prostanoids acting on the Tp receptor (Yang et al. 2002); however, further studies are needed to support this proposed mechanism. These results have not been observed for oleanolic acid.

The relationship between vascular endothelium and oxygen-derived free radicals is known (Mombouli \& Vanhoutte, 1999; Vanhoutte, 2001). Superoxide anions are known to be implicated in the breakdown of NO (Laight et al. 1998). Moreover, superoxide anions are the source of the secondary reactive oxygen species such as $\mathrm{H}_{2} \mathrm{O}_{2}$ and hydroxyl radicals (Yang et al. 2002). Therefore, one of our hypotheses was that oleanolic acid and erythrodiol may mediate their vascular effects via the protection of NO breakdown by superoxide anions, since these triterpenoids, mainly oleanolic acid, have shown an antioxidant activity (Somova et al. 2003a,b). In our experimental conditions, the use of the superoxide anion and $\mathrm{H}_{2} \mathrm{O}_{2}$ scavengers, SOD and catalase, did not modify the relaxations caused by oleanolic acid and erythrodiol. Thus, these results ruled out a mechanism sensitive to exogenous SOD and catalase even though a participation of intracellular reactive oxygen species insensitive to these scavengers cannot be excluded.

In order to clarify the mechanism of relaxation, we have also considered the involvement of intracellular $\mathrm{Ca}^{2+}$ 
concentration in the endothelial cell induced by oleanolic acid and erythrodiol. For this purpose, we have used cyclopiazonic acid, which is a specific inhibitor of the sarcoplasmic reticulum $\mathrm{Ca}^{2+}$-ATPase. The endothelium-dependent relaxation induced by oleanolic acid and erythrodiol was significantly reduced by incubating the aortic rings with cyclopiazonic acid. In blood vessels, $\mathrm{Ca}^{2+}$ release and the subsequent increase in cytosolic $\mathrm{Ca}^{2+}$ concentration in endothelial cells could activate $\mathrm{NO}$ synthase and induce the NO-mediated relaxation of aortic rings (Lückhoff et al. 1988; Zheng et al. 1994). These data suggest that the effects of these triterpenoids on the $\mathrm{Ca}^{2+}$ homeostasis of endothelial cells might contribute to vasodilatation. Therefore, oleanolic acid and erythrodiol might inhibit the sequestration of $\mathrm{Ca}^{2+}$ into intracellular stores via sarcoplasmic reticulum $\mathrm{Ca}^{2+}-\mathrm{ATPase}$, thus increasing intracellular $\mathrm{Ca}^{2+}$ in endothelial cells, and with the subsequent NO synthase activation and NO release.

In conclusion, the results of the present study introduce the first in vitro evidence that oleanolic acid and erythrodiol evoke an endothelium-dependent vasorelaxation in rat aorta. These preliminary results suggest that the mechanism of relaxation seems to be mainly mediated by the endothelial production of NO; however, other mechanisms cannot be excluded. Bearing in mind the pharmacological effects showed earlier, it can be concluded that oleanolic acid and erythrodiol may have interesting therapeutic potential as new vasodilator drugs, thus protecting the cardiovascular system. Therefore, the intake of 'orujo' olive oil, as a source of these compounds, might be beneficial in this regard. Additional experimentation is in progress in order to provide new data for clarifying the precise mechanism by which oleanolic acid and erythrodiol produce their characteristic in vitro vasorelaxant effects.

\section{Acknowledgements}

The present study was supported by funds from the Comisión Interministerial de Ciencia y Tecnología (CICYT) (project AGL2002-00195) and Junta de Andalucía (CAO01-002).

\section{References}

Álvarez de Sotomayor M, Pérez-Guerrero C, Herrera MD \& Marhuenda E (2001) Effect of simvastatin on vascular smooth muscle responsiveness: involvement of $\mathrm{Ca}(2+)$ homeostasis. Eur J Pharmacol 415, 217-224.

American Dietetic Association (1999) Position of the American Dietetic Association: functional foods. J Am Diet Assoc 99, $1278-1285$.

Boulanger CM (1999) Secondary endothelial dysfunction: hypertension and heart failure. J Mol Cell Cardiol 31, 39-49.

Choi CY, You HJ \& Jeong HG (2001) Nitric oxide and tumor necrosis factor-alpha production by oleanolic acid via nuclear factor-kappaB activation in macrophages. Biochem Biophys Res Commun 288, 49-55.

De la Puerta R, Martínez-Domínguez E \& Ruíz-Gutiérrez V (2000) Effect of minor components of virgin olive oil on topical antiinflammatory assays. $Z$ Naturforsch $\mathbf{5 5 C}$ 814-819.

De la Puerta R, Ruíz-Gutiérrez V \& Hoult JRS (1999) Inhibition of leukocyte 5-lipooxygenase by phenolics from virgin olive oil. Biochem Pharmacol 57, 445-449.

Furchgott RF \& Vanhoutte PM (1989) Endothelium-derived relaxing and contracting factors. FASEB J 3, 2007-2018.

Furchgott RF \& Zawadzki JV (1980) The obligatory role of endothelial cells in the relaxation of arterial smooth muscle by acetylcholine. Nature 299, 373-376.

Godfraind T, Miller R \& Wibo M (1986) Calcium antagonism and calcium entry blockade. Pharmacol Rev 38, 321-416.

Honda T, Rounds BV, Bore L, Finlay HJ, Favaloro FG Jr, Suh N, Wang Y, Sporn MB \& Gribble GW (2000) Synthetic oleanane and ursane triterpenoids with modified rings $\mathrm{A}$ and $\mathrm{C}$ : a series of highly active inhibitors of nitric oxide production in mouse macrophages. J Med Chem 43, 4233-4246.

Hsu HY, Yang JJ \& Lin CC (1997) Effects of oleanolic acid and ursolic acid on inhibiting tumor growth and enhancing the recovery of hematopoietic system postirradiation in mice. Cancer Lett 111, 7-13.

Kashiwada Y, Wang HK, Nagao T, et al. (1998) Anti-AIDS agents. 30. Anti-HIV activity of oleanolic acid, pomolic acid, and structurally related triterpenoids. J Nat Prod 61, 1090-1095.

Keys A (1995) Mediterranean diet and public health: personal reflections. Am J Clin Nutr 61, 1321S-1323S.

Kim ND, Kang SY \& Schini VB (1994) Gingenosides evoke endothelium-dependent vascular relaxation in rat aorta. Gen Pharmacol 25, 1071-1077.

Laight DW, Kaw AV, Carrier MJ \& Anggard EE (1998) Interaction between superoxide anion and nitric oxide in the regulation of vascular endothelial function. Br J Pharmacol 124, $238-244$.

Libby P (2002) Inflammation and atherosclerosis. Nature 420, $868-874$.

Liu J (1995) Pharmacology of oleanolic acid and ursolic acid. J Ethnopharmacol 49, 57-68.

Liu Y, Hartley DP \& Liu J (1998) Protection against carbon tetrachloride hepatotoxicity by oleanolic acid is not mediated through metallothionein. Toxicol Lett 95, 77-85.

Lückhoff A, Pohl U, Mulsch A \& Busse R (1988) Differential role of extra- and intracellular calcium in the release of EDRF and prostacyclin from cultured endothelial cells. $\mathrm{Br} J$ Pharmacol 95, 189-196.

Lüscher TF \& Barton M (1997) Biology of the endothelium. Clin Cardiol 20, Suppl. 2, II-3-II-10.

Mañez S, Recio MC, Giner RM \& Ríos JL (1997) Effect of selected triterpenoids on chronic dermal inflammation. Eur $J$ Pharmacol 334, 103-105.

Matsuda H, Li Y, Murakami T, Matsumura N, Yamahara J \& Yoshikawa M (1998) Antidiabetic principles of natural medicines. III. Structure-related inhibitory activity and action mode of oleanolic acid glycosides on hypoglycemic activity. Chem Pharm Bull (Tokyo) 46, 1399-1403.

Mengoni F, Lichtner M, Battinelli L, Marzi M, Mastroianni CM, Vullo V \& Mazzanti G (2002) In vitro anti-HIV activity of oleanolic acid on infected human mononuclear cells. Planta Med 68, 111-114.

Mombouli JV \& Vanhoutte PM (1999) Endothelial dysfunction: from physiology to therapy. J Mol Cell Cardiol 31, 61-74.

Moncada S, Palmer RM \& Higgs EA (1991) Nitric oxide: physiology, pathophysiology, and pharmacology. Pharmacol Rev 43, 109-142.

Pérez-Camino MC \& Cert A (1999) Quantitative determination of hydroxy pentacyclic triterpene acids in vegetable oils. J Agric Food Chem 47, 1558-1562.

Perona JS \& Ruíz-Gutiérrez V (2000) Effect of two high-oleic oils on the liver lipid composition of spontaneously hypertensive rats. Life Sci 66, 521-531.

Recio MC, Giner RM, Mañez S \& Rios JL (1995) Structural 
requirements for the anti-inflammatory activity of natural triterpenoids. Planta Med 61, 182-185.

Ringbom T, Segura L, Noreen Y, Perera P \& Bohlin L (1998) Ursolic acid from Plantago major, a selective inhibitor of cyclooxygenase- 2 catalyzed prostaglandin biosynthesis. $J$ Nat Prod 61, 1212-1215.

Somova LI, Nadar A, Rammanan P \& Shode FO (2003a) Cardiovascular, antihyperlipidemic and antioxidant effects of oleanolic and ursolic acids in experimental hypertension. Phytomedicine 10, 115-121.

Somova LI, Shode FO, Ramnanan P \& Nadar A (2003b) Antihypertensive, antiatherosclerotic and antioxidant activity of triterpenoids isolated from Olea europaea, subspecies africana leaves. J Ethnopharmacol 84, 299-305.

Tanner MA, Bu X, Steimle JA \& Myers PR (1999) The direct release of nitric oxide by gypenosides derived from the herb Gynostemma pentaphyllum. Nitric Oxide 3, 359-365.

Vanhoutte PM (2001) Endothelium-derived free radicals: for worse and for better. J Clin Invest 107, 23-25.

Vázquez-Roncero A \& Janer ML (1969) Ácidos triterpénicos del olivo (Triterpenoid acids of the olive tree). Grasas y Aceites 20, $133-138$.

Vioque E \& Maza MP (1963) Sobre los ácidos triterpénicos del aceite de orujo y oliva (About orujo and olive oil triterpenic acids). Grasas y Aceites 14, 9-11.
Vioque E \& Morris LJ (1961) Minor components of olive oils. I. Triterpenoid acids in an acetone-extracted orujo oil. $J$ Am Oil Chem Soc 38, 485-488.

Visioli F \& Galli C (1998) The effect of minor constituents of olive oil on cardiovascular disease: new findings. Nutr Rev 56, 142-147.

Yang D, Feletou M, Boulanger CM, Wu HF, Levens N, Zhang JN \& Vanhoutte PM (2002) Oxygen-derived free radicals mediate endothelium-dependent contractions to acetylcholine in aortas from spontaneously hypertensive rats. Br J Pharmacol 136, $104-110$.

Yim TK, Wu WK, Pak WF \& Ko KM (2001) Hepatoprotective action of an oleanolic acid-enriched extract of Ligustrum lucidum fruits is mediated through an enhancement on hepatic glutathione regeneration capacity in mice. Phytother Res 15, 589-592.

Yoshikawa M \& Matsuda H (2000) Antidiabetogenic activity of oleanolic acid glycosides from medicinal foodstuffs. Biofactors 13, 231-237.

Zheng XF, Kwan CY \& Daniel EE (1994) Role of intracellular $\mathrm{Ca}^{2+}$ in EDRF release in rat aorta. $J$ Vasc Res 31, 18-24.

Zhu YM, Shen JK, Wang HK, Cosentino LM \& Lee KH (2001) Synthesis and anti-HIV activity of oleanolic acid derivatives. Bioorg Med Chem Lett 11, 3115-3118. 